\title{
Different Innate Immune Responses in BALB/C and C57BL/6 Strains following Corneal Transplantation
}

\author{
Tim Bleul Xinyu Zhuang Antonia Hildebrand Clemens Lange \\ Daniel Böhringer Günther Schlunck Thomas Reinhard Thabo Lapp \\ Eye Center, Medical Center, Faculty of Medicine, University of Freiburg, Freiburg im Breisgau, Germany
}

\section{Keywords}

Keratoplasty Corneal graft rejection · Macrophage . $\mathrm{C} 57 \mathrm{BL} / 6 \cdot \mathrm{BALB} / \mathrm{C}$

\begin{abstract}
Purpose: To investigate immunological differences and the role of CD38+/F4/80 + M1 macrophages in C57BL/6J- and BALB/c-recipient mouse corneal transplantation models. Methods: Allogeneic transplantation was performed crosswise in BALB/C mice and C57BL/6J mice; syngeneic transplantation was performed in both strains. Anterior chamber depth (ACD) was measured before and central corneal thickness (CCT) was measured both before and after transplantation. In vivo graft rejection was monitored using anterior eye segment optical coherence tomography (ASOCT) evaluating the CCT and grading of corneal oedema using a well-established clinical score (CS). Histology of corneal grafts was performed 18 or 21 days after surgery. Immunohistochemistry with anti-F4/80 antibody and anti-CD38 antibody was used for detecting M1 macrophages within the grafts. Results: High CS and CCT values after allogeneic transplantation persisted in both BALB/C $(n=18)$ and C57BL/6J recipients $(n=$
\end{abstract}

karger@karger.com www.karger.com/jin

Karger $\stackrel{\text { ' }}{5}$

GOPEN ACCESS
(C) 2020 The Author(s)

Published by S. Karger AG, Basel

This article is licensed under the Creative Commons AttributionNonCommercial-NoDerivatives 4.0 International License (CC BYNC-ND) (http://www.karger.com/Services/OpenAccessLicense). Usage and distribution for commercial purposes as well as any distribution of modified material requires written permission.
20). After syngeneic transplantation, CS and CCT values increased in both models in the early phase after surgery due to the surgical trauma. Surprisingly, in the syngeneic C57BL/6J model, high CCT values persisted. Furthermore, anterior synechiae developed in C57BL/6 recipients after both syngeneic and allogeneic transplantation, whereas $B A L B / C$ recipients showed almost no synechiae - even though C57/BL6J animals tended to have a deeper anterior chamber (281 \pm 11 pixels [mean \pm SD]) compared with $B A L B / C$ animals of the same age ( $270 \pm 9$ pixels [mean $\pm S D$ ]). Immunohistochemistry revealed numerous CD38+/F4/80 + M1 macrophages in grafts of C57BL/6J recipients following both syngeneic and allogeneic transplantation. However, in BALB/C-recipient mice only sparse M1 macrophages were detectable $(\mathrm{CD} 38+\mathrm{M} 1$ macrophages relative to all F4/80 + cells: 75 vs. $17 \%$ [after allogeneic transplantation] and 66 vs. $17 \%$ [after syngeneic transplantation]; $p<0.05$ ). Conclusions: Allogeneic corneal transplants are rejected in BALB/C as well as $\mathrm{C} 57 \mathrm{BL} / 6 \mathrm{~J}$ mice, but tissue alterations with anterior synechiae are more pronounced in $\mathrm{C} 57 \mathrm{BL} / 6 \mathrm{~J}$ recipients. Fol-

Tim Bleul and Xinyu Zhuang contributed equally to this work. 
lowing syngeneic transplantation, C57BL/6J-recipient animals show a persistent graft swelling with increased numbers of $C D 38+/ F 4 / 80+M 1$ macrophages in grafted tissue, in contrast to the common model using BALB/c-recipient mice. Our data strongly suggest that strain-dependent differences convey different innate immune responses in BALB/C and $\mathrm{C} 57 \mathrm{BL} / 6 \mathrm{~J}$ strains. Accordingly, in murine keratoplasty experiments, the mouse line of both donor and recipient animals must be carefully considered. C57BL/6J-recipient mice might be particularly suited to study corneal graft rejection in a clinical setting considered "high risk."

(C) 2020 The Author(s)

Published by S. Karger AG, Basel

\section{Introduction}

Corneal transplantation is one of the most commonly performed forms of tissue transplantation worldwide [1] and enjoys a 10-year graft survival rate of $~ 90 \%$ in lowrisk situations. However, the rejection rate is over $50 \%$ in high-risk hosts such as those with corneal ulcers, corneal vascularization, or a history of graft rejections. This occurs despite maximal topical and systemic immune suppression [2]. Corticosteroids are the commonly used treatment for acute rejection [3]. Applied systemically or locally, they also cause adverse effects, such as cataract, steroid response with an increased intraocular pressure, and secondary infections $[4,5]$. Thus, it is imperative to develop new strategies for preventing or treating corneal graft rejection.

Most of the research in corneal transplantation and in conducting research on pharmacological interventions is performed using mouse models, with $\mathrm{C} 57 \mathrm{BL} / 6$ and $\mathrm{BALB} / \mathrm{c}$ mice most frequently used as recipients [6-9]. In murine keratoplasty, a $2.0-2.5-\mathrm{mm}$ graft is obtained from the donor animal and sutured into the recipient animal by interrupted sutures. Usually, allogeneic mouse strains are transplanted [10], while syngeneic animals serve as controls. In case of rejection, the transplant is subsequently clouded due to an immune reaction. This clouding is the result of cellular infiltration of the graft as well as immune-cell-induced damage to the endothelium of the graft, which leads to oedema [11]. Until now, the readout parameter "opacity" has only been assessed semiquantitatively by means of a score; more recent work has also established anterior eye segment optical coherence tomography (ASOCT) for measuring thickness of the rejected graft in order to generate a parameter that can be documented and standardized [12]. Regarding the use of individual mouse strains, there is neither standardization nor are there any studies comparing immune reactions between mouse strains.

In the 1980s, Scott and Farrell [13] and Heinzel et al. [14] observed that C57BL/6 mice are resistant to leishmanial major infections, whereas $\mathrm{BALB} / \mathrm{c}$ mice die after infection with the same pathogen. Compared with $\mathrm{BALB} / \mathrm{c}$ mice, $\mathrm{C} 57 \mathrm{BL} / 6$ mice also showed stronger protection against melanoma metastases and higher resistance to various types of infection, including tuberculosis, Pasteurella pneumotropica, and Chlamydia [15-18]. Other studies revealed that in contrast to $\mathrm{C} 57 \mathrm{BL} / 6$ mice, which show a Th1- and M1-dominant immune response, $\mathrm{BALB} / \mathrm{c}$ mice show a more Th2- and M2-dominant immune response $[17,19]$. The differences in susceptibility strongly indicate significant differences in the innate immune system function, which were eventually attributed to $\mathrm{M} 1 / \mathrm{M} 2$ differences.

As of 2019, 4 studies comprising a murine keratoplasty model were published (Table 1). Half of them grafted $\mathrm{C} 57 \mathrm{BL} / 6$ donor tissue into $\mathrm{BALB} / \mathrm{c}$ recipients. Both mouse strains are the de facto standard to investigate the innate immune system and immunological processes during graft rejection. However, it remains unclear to what extent these models are mimicking immunological mechanisms during corneal graft rejection in humans and if the differences in the innate immune system of these 2 mouse strains affect the outcome after corneal transplantation. In the present study, we therefore compared the outcome of corneal transplantation after syngeneic and allogeneic transplantation into $\mathrm{BALB} / \mathrm{c}$ or C57BL/6J mice, respectively. In addition, we investigated the macrophage subtypes in rejected corneal grafts.

\section{Materials and Methods}

\section{Ethics}

All animal experiments were approved by the Faculty of Medicine, University of Freiburg, and the federal state of Baden-Württemberg represented by the regional council Freiburg. This animal study was conducted in accordance with the ARVO Statement for the Use of Animals in Ophthalmic and Vision Research. Animals were also treated in compliance with German, European, and Federation of Laboratory Animal Science Associations (LAS) regulations for the care of experimental animals.

\section{Animals}

Inbred adult female C57BL/6J mice (Charles River, Sulzfeld, Germany) and female BALB/c mice (Charles River, Sulzfeld, Germany) were used for syngeneic or allogeneic transplantation. All animals were 6-12 weeks old; the exact age and weight of the animals used can be found in online suppl. Fig. 1; for all online suppl. material, see www.karger.com/doi/10.1159/000509716.
J Innate Immun 2021;13:49-59 DOI: $10.1159 / 000509716$
Bleul/Zhuang/Hildebrand/Lange/ Böhringer/Schlunck/Reinhard/Lapp 
Table 1. Mouse models used to investigate corneal transplantation [7, 12, 20-28]

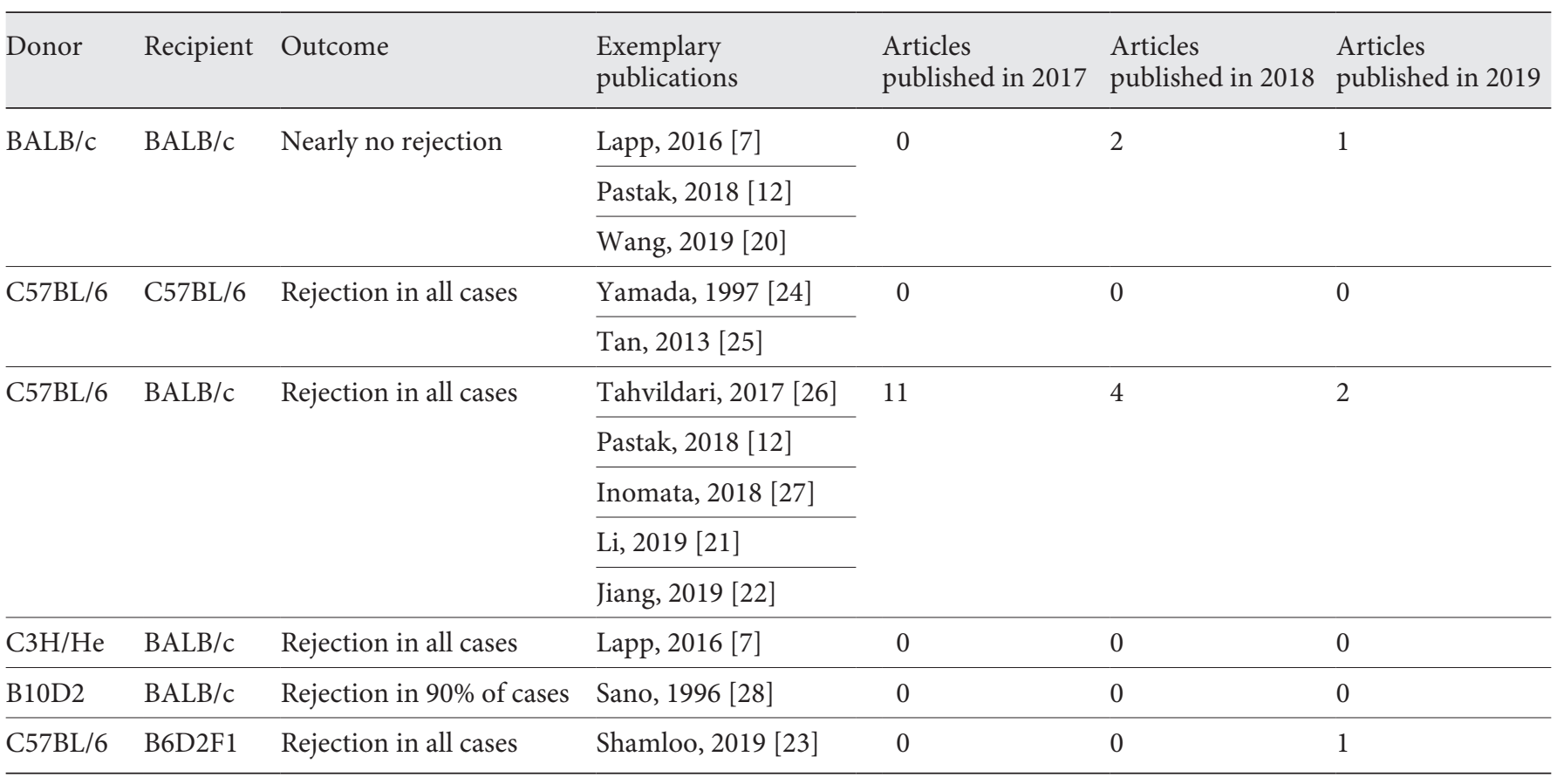

\section{Orthotopic Corneal Transplantation}

Syngeneic and allogeneic corneal transplantation was performed as described previously [12]. Corneal transplantation was performed in only one eye per animal in accordance with Animal Welfare Regulations. In brief, anaesthesia was performed by injecting $10 \mathrm{mg} / \mathrm{kg}$ body weight xylazine (Bayer, Leverkusen, Germany) and $100 \mathrm{mg} / \mathrm{kg}$ body weight ketamine (Essex, München, Germany) intraperitoneally. A 2.0-mm diameter central corneal graft from the donor was placed into a $1.5-\mathrm{mm}$ recipient corneal bed and sutured with 8 interrupted 11-0 nylon sutures (ETHILON $^{\circledR}$ Nylon Suture, Ethicon Inc., Somerville, NJ, USA). All corneas were completely clear before grafting. Following surgery, ofloxacin ointment (Floxal, Dr. Gerhard Mann, Chem.-pharm. $\mathrm{GmbH}$, Germany) was applied once to the cornea. The eyelids were closed with a 7.0 SERALON ${ }^{\circledR}$ suture (Serag-Wiessner GmbH \& Co. KG, Naila, Germany) to protect the surgical area for $72 \mathrm{~h}$. After suture removal, the eyes were examined using a surgical microscope from the third post-operative day and every 3 days afterwards. Animals exhibiting surgical complications, such as intraocular haemorrhage, signs of infection, collapse of the anterior chamber, or cataract, were excluded. In total, we included 18 $\mathrm{BALB} / \mathrm{c}$ mice (10 syngeneic and 8 allogeneic) and $20 \mathrm{C} 57 \mathrm{BL} / 6 \mathrm{~J}$ mice (10 per group).

\section{Clinical Score, Central Corneal Thickness, and Anterior}

Chamber Depth Measurement

Evaluation of the corneal opacity was performed as previously described [12]. In brief, the opacity of corneas was assessed according to the following scoring system using a slit-lamp biomicroscope (Table 2). Onset of graft rejection was defined when the corneal opacity exceeded grade 2 (no iris vessels discernible).

Immunological Confounders in Murine Keratoplasty Models
Table 2. Definition of the clinical score

Grade Clinical description

$0 \quad$ Completely transparent cornea

$1 \quad$ Minimal corneal opacity with iris vessels easily detectable

$2 \quad$ Visible moderate corneal opacity with iris vessels still visible

3 Moderate corneal opacity with only the pupillary margin visible

4 Complete corneal opacity, pupil not visible

For ASOCT measurements, animals were anesthetized as described above and analyzed using a Micron IV Retinal Imaging System (Phoenix Research Laboratories, Pleasanton, CA, USA) and an Image-Guided OCT for mice (Cat. No. 9002; Phoenix Research Laboratories). To ensure that only the central areas of the graft were measured when determining the corneal thickness, the cutting axis was additionally monitored by means of a visual image during the measurement. Tomographic images were used to measure transplant thickness in pixels, defined in a central vertical section using Cell Finder software [29]. Since ASOCT tends to distort anatomic structures, we excluded systemic errors by measuring the vertical and the horizontal central CCT at the same time and used both measurements to calculate the average central thickness. ASOCT was performed every 3 days starting with day 6 after transplantation. The ACD was measured using the same technique. 

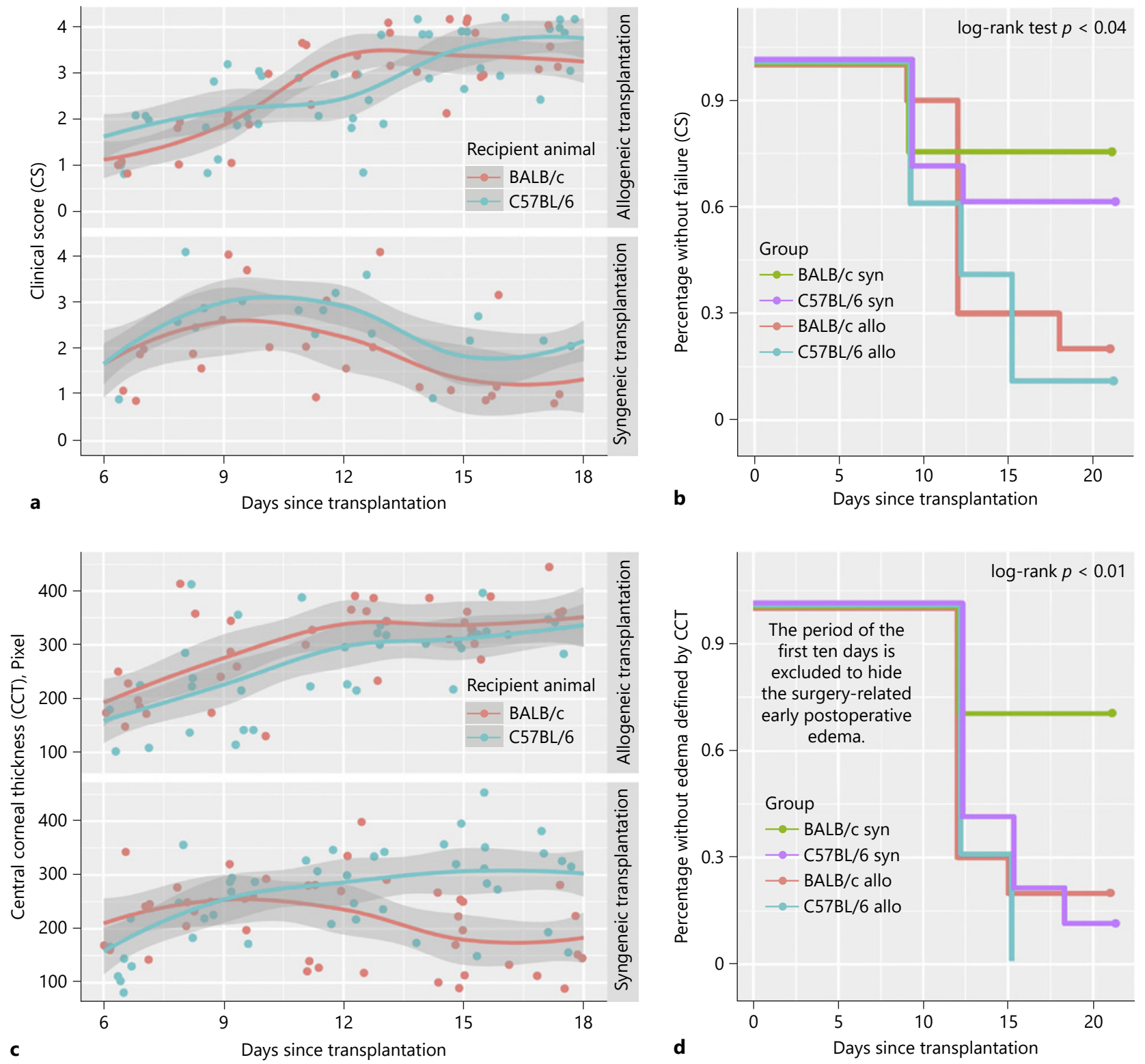

Fig. 1. CCT, CS, and corresponding Kaplan-Meier estimates. CS (a) and CCT (c) are displayed from the 6th to the 18th day after surgery. Each point represents a post-operative examination; points are jittered to prevent overplotting $(n=18 \mathrm{BALB} / \mathrm{c}$ mice and $20 \mathrm{C} 57 \mathrm{BL} / 6 \mathrm{~J}$ mice). The grey ribbons indicate the standard error of the mean $(\mathbf{a}, \mathbf{c})$. The statistics for the corresponding Kaplan-

\section{Histology and Immunohistochemistry}

The animals were sacrificed by cervical dislocation, and eyeballs were harvested 18 and 21 days after transplantation. Staining for histology was performed in $10 \mathrm{BALB} / \mathrm{c}$ and $10 \mathrm{C} 57 \mathrm{BL} / 6 \mathrm{~J}$ mice ( 5 syngeneic and 5 allogeneic animals per group, respectively). All specimens collected were frozen in Tissue-Tek ${ }^{\circledR}$
Meier estimates (defined by the CS in $\mathbf{b}$ and by the transplant oedema in d) were calculated using a log-rank test. With regard to transplant swelling, the first 10 days were excluded in the KaplanMeier estimate to exclude errors related to corneal oedema caused by surgery (d). CCT, central corneal thickness; CS, clinical score.

O.C.T. ${ }^{\text {TM }}$ Compound (Sakura Finetek Europe, Alphen aan den Rijn, The Netherlands) and stored at $-20^{\circ} \mathrm{C}$. For histology, globes were cut in half and sections of 6- $\mu \mathrm{m}$ thickness were cut in a Microtome 3050S (Leica, Wetzlar, Germany) beginning from the central cornea towards the periphery. The sections were stained with haematoxylin and eosin (H\&E) or periodic acid-Schiff and 
examined with a light microscope. Corneal thickness evaluation was performed only in central sections of the graft; for anterior chamber and synechia assessment, histological sections from the center to the periphery were scanned to avoid missing peripheral synechiae. For immunohistochemistry, sections were blocked using $1 \%$ BSA and $0.3 \%$ Tween in PBS for $60 \mathrm{~min}$. Thirteen sections (3 BALB/c syngeneic and 3 allogeneic, as well as 3 C57BL/6J syngeneic and 4 allogeneic) were incubated with antimouse F4/80 (1:200, rabbit monoclonal to mouse, Abcam: ab111101), anti-mouse CD68 (1:200, CD68 polyclonal antibody, rabbit/IgG, Invitrogen: PA532330), or anti-mouse CD38 (1:100, rat monoclonal to mouse, Lifespan Biosciences: LS-C43670) at $+4^{\circ} \mathrm{C}$ overnight. After washing 3 times in PBS and $0.1 \%$ Tween, the corneas were incubated with Anti-Rabbit Alexa 488 (1:500, Donkey Anti-Rabbit IgG $(\mathrm{H}+\mathrm{L})$ Highly Cross-Adsorbed Secondary Antibody, Alexa Fluor 488, Invitrogen: A21206) and Anti-Rat Cy3 (1:500, Donkey Anti-Rat IgG (H + L) Cy3 Affinity Purified $\mathrm{F}\left(\mathrm{ab}^{\prime}\right) 2$ Fragment, Jackson ImmunoResearch: 712-166$150)$ for $1 \mathrm{~h}$ at room temperature. The samples were mounted in Mowiol supplemented with $0.1 \%$ DAPI.

\section{Statistical Analysis and Data Plotting}

Data from the clinical score (CS) and the central corneal thickness (CCT) were analyzed descriptively using the R system [30], package ggplot2 [31] and Hmisc [32]. We used the KruskalWallis test to compare numerical data between groups and Kaplan-Meier curves to visualize the respective incidence rates. These curves were statistically tested using the log-rank test. Data were calculated and plotted using the $\mathrm{R}$ platform as mentioned above.

\section{Results}

\section{Dynamics of Corneal Graft Rejection in Both Recipient Strains}

To investigate whether mouse strains show a different level of inflammation after syngeneic or allogeneic transplantation, we examined the CS and CCT of grafts using ASOCT every 3 days from day 6 to day 18 after surgery. We observed no relevant differences between allogeneic models with regard to the CS (Fig. 1a, upper 2 curves) and the CCT (Fig. 1c, upper 2 curves). Kaplan-Meier estimations confirmed this course for CS (Fig. 1b), allowing differentiation between syngeneic and allogeneic transplantation ( $p<0.04$, log-rank test) and showing fewer events in both BALB/c groups in comparison with the C57BL/6 groups. In syngeneic models, the CS between the 2 mouse strains showed no difference (Fig. 1a, lower 2 curves). However, CCT, which is more objective and repeatable [12], was higher in C57BL/6J mice (Fig. 1c, lower 2 curves) and remained higher from day 15 onward. This finding was confirmed in the Kaplan-Meier estimation $(p<0.01$, log-rank test).

Immunological Confounders in Murine Keratoplasty Models

\section{Histopathology}

H\&E staining was performed on corneal grafts 18 or 21 days after transplantation. Examples of H\&E staining are shown in Figure 2. Two schematic drawings (1 normal mouse eye and 1 transplanted eye) and a histological overview illustrate the relevant structures. The border between the transplant and the recipient cornea can be determined in the histological overview.

In the course of transplant rejection, inflammatory infiltration and swelling of the transplant occur. This swelling and cell infiltration are more pronounced after allogeneic (Fig. 2al, b1) than after syngeneic (Fig. 2c1, d1) transplantation. For C57BL/6J mice, anterior synechiae were much more prominent after allogeneic transplantation than after syngeneic transplantation (see Fig. 2b1, b4, $\mathrm{d} 4$ and asterisks in Fig. 2d1). In the syngeneic group, 5 out of 10 C57/BL6-recipient mice and 1 out of $10 \mathrm{BALB} / \mathrm{c}-$ recipient mice showed synechiae, whereas in the allogeneic group, the ratio was 8 out of 10 in the $\mathrm{C} 57 \mathrm{BL} / 6$ group and 1 out of 10 in the BALB/c group.

\section{Anatomical Influences as Possible Confounders}

To exclude any possible anatomical confounders, control CCT and anterior chamber depth (ACD) were measured before transplantation (see Fig. 3). CCTs of these 2 mouse strains ( $n=10$ animals per group) were almost the same with an average value at about 60 pixels (see right boxes in Fig. 3; $p=0.72$, Kruskal-Wallis test). The ACD ( $n=12$ animals per group) showed no statistically relevant difference either, but C57BL/6J animals tended to have a deeper anterior chamber, making the formation of anterior synechiae even less likely (see left boxes in Fig. 3; $p=0.06$, Kruskal-Wallis test).

\section{Immunohistochemistry}

To characterize infiltrating immune cells, anti-F4/80 and anti-CD38 antibodies were used for immunohistochemistry (see Fig. 4). F4/80 antigens have been widely used to detect macrophages in tissues, while CD38 is a novel marker for M1 macrophages [46-50]. We found almost no double-positive cells in corneas from syngeneic- and allogeneic-transplanted $\mathrm{BALB} / \mathrm{c}$ mice (see Fig. 4a3, c3, e) but a significant number of double-positive immune cells in both C57BL/6J groups (see Fig. 4b3, d3, e; $p=0.03$ in the allogeneic group and $p=0.07$ in the syngeneic group; Kruskal-Wallis test). In untreated, nontransplanted animals, only sparsely F4/80 + antigen-presenting cells (APC) are present in both BALB/c and C57/ BL6 animals; additional staining for CD68 did not indicate the presence of APC either (see Fig. 4f1-4).

J Innate Immun 2021;13:49-59 


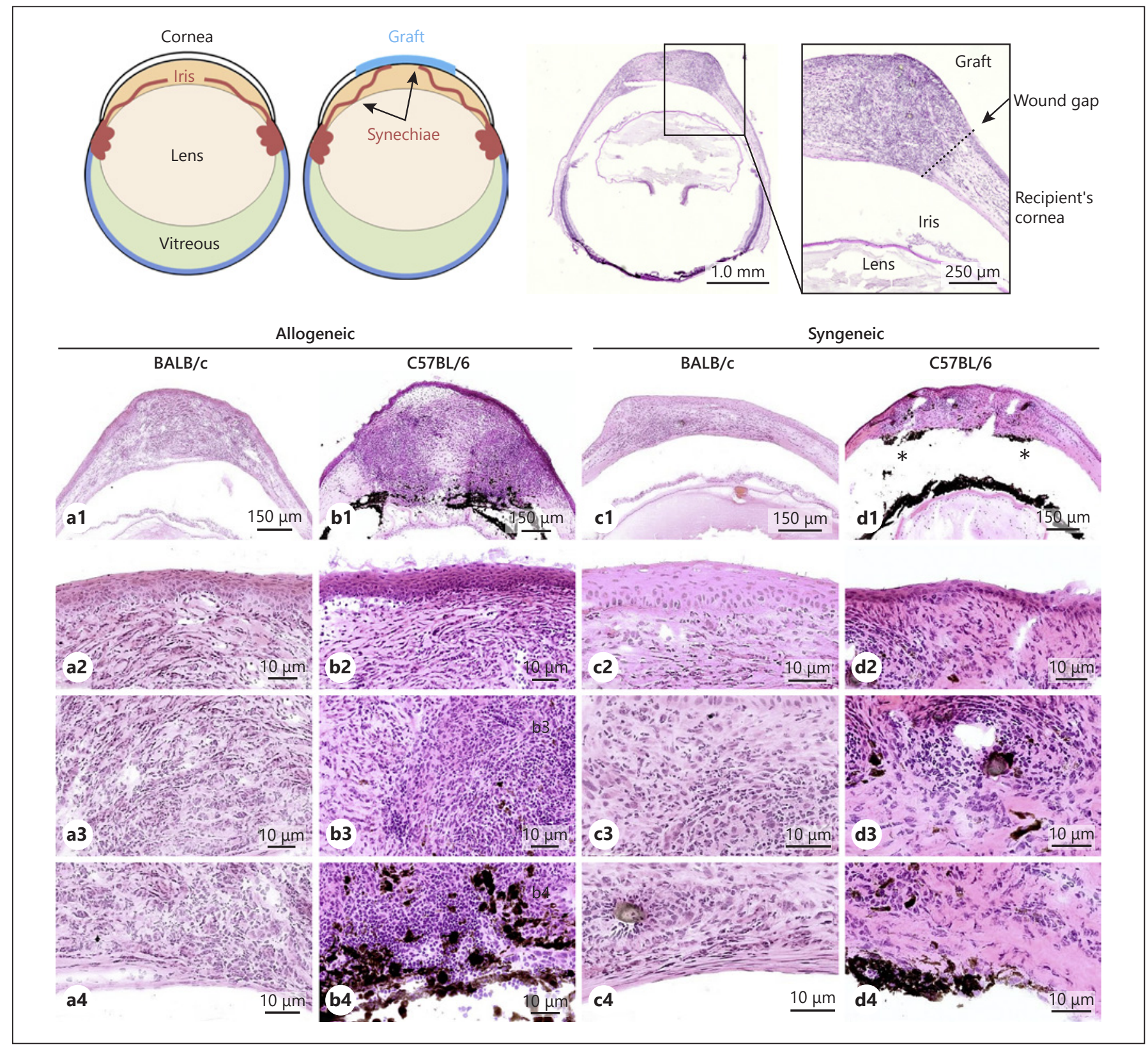

Fig. 2. Histology of eyes 18 to 21 days after corneal transplantation. The schematic drawing and the histological overview provide an insight into the anatomical structures. After allogeneic transplantation $(\mathbf{a}, \mathbf{b})$, there is a distinct swelling of the graft in both mouse lines; this swelling is less pronounced after syngeneic transplantation $(\mathbf{c}, \mathbf{d})$. The dark pigmentation of the iris allows the recognition of the $\mathrm{C} 57 \mathrm{BL} / 6$ animals; in the $\mathrm{BALB} / \mathrm{c}$ animals, the iris has almost

\section{Discussion}

Our study revealed significant strain-dependent differences in the innate immune response following mu- no pigmentation. After transplantation, anterior synechiae (b1 and asterisk in d1) occur mostly in C57BL/6 animals. Figures 2-4 show further details; the epithelium is located in 2, the stroma in 3 , and the endothelium - if still present - in 4 . Note the pigment adhesions to the endothelium, which are a result of the synechiae (b4 and d4). Representative images of a total of $n=10 \mathrm{BALB} / \mathrm{c}$ and $n=10 \mathrm{C} 57 \mathrm{BL} / 6 \mathrm{~J}$ mice per group are given.
54

J Innate Immun 2021;13:49-59

DOI: $10.1159 / 000509716$
Bleul/Zhuang/Hildebrand/Lange/ Böhringer/Schlunck/Reinhard/Lapp 
Fig. 3. $\mathrm{ACD}(\mathbf{a})$ and $\mathrm{CCT}(\mathbf{b})$ of $\mathrm{BALB} / \mathrm{c}$ and C57/BL6J mice prior to surgery. Box and whiskers plots of ACD and CCT before transplantation of both murine models revealed no statistically significant differences. The ACD even turned out to be higher in $\mathrm{C} 57 \mathrm{BL} / 6$ mice in comparison with $\mathrm{BALB} / \mathrm{c}$ mice. CCT, central corneal thickness; ACD, anterior chamber depth.

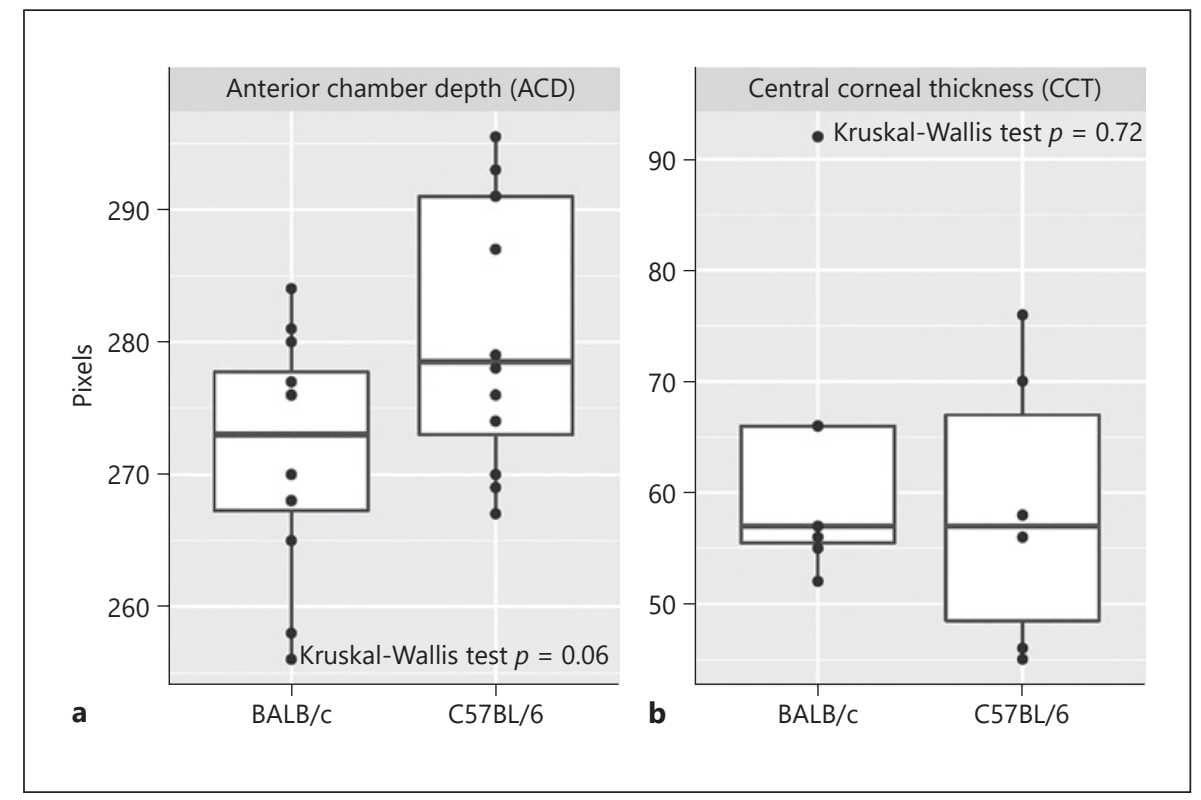

nounced in syngeneic corneal transplants in BALB/c-recipient mice compared with $\mathrm{C} 57 \mathrm{BL} / 6 \mathrm{~J}-$ recipient mice. This is of particular interest since various recipient and donor mouse strains have been used in previously published studies neglecting possible confounders related to the innate immune response following corneal transplantation in mice.

When evaluating corneal graft rejection in mice, using a subjective CS system has been the gold standard. This CS system describes the corneal opacity through integration of the underlying parameter oedema due to an endothelial dysfunction as well as a cellular infiltration. In contrast, the ASOCT objectively measures the CCT as readout for corneal swelling and has a significantly higher resolution with regard to the degree of tissue changes than the CS [12]. In our study, both the CS as well as the CCT values of allogeneic models increased until day 18 , suggesting an aggravated and ongoing inflammation within the graft after allogeneic transplantation. In corresponding OCT images, allogeneic grafts appeared thick with the Descemet membrane being unrecognizable.

CS and CCT values of the syngeneic models were always lower than the corresponding allogeneic models. The peak of CCT after syngeneic transplantation appeared right after transplantation, being most likely related due to the surgical manipulation. The CS and CCT of BALB/c syngeneic grafts decreased afterwards. However, although the CS of C57BL/6 syngeneic model declined after the early phase, the CCT did not. It is important to point out that possible anatomical confounders leading to increased inflammation and anterior synechia formation such as pre-operative CCT or ACD were ruled out in this study. There was no statistical difference in pre-operative CCT or ACD between the 2 mouse strains indicating that the differences in corneal oedema and anterior synechiae between strains were most likely due to different levels of inflammation following corneal transplantation.

Analyzing the immune response following allogeneic transplantation, rejection occurs as published, but inflammation as well as formation of anterior synechiae is more pronounced in C57BL/6J-recipient mice, suggesting a different aggressiveness of rejection. This may also be a reason for the predominant use of BALB/c-recipient mice reported in the literature. Using histology and immunohistochemistry, our observations suggest that rejection intensity correlates with the presence of M1 macrophages. This finding is in line with earlier reports of differing innate immune system activation after infection with various pathogens and the reported M1/M2 differences in $\mathrm{BALB} / \mathrm{c}$ and $\mathrm{C} 57 \mathrm{BL} / 6$ mice [10-16]. The origin of these M1 macrophages in C57BL/6 animals cannot be answered definitively. However, in line with the previous observation that M1 macrophages dominate the response in C57BL/6 animals to bacterial challenge, our data suggest that graft rejection is also dominated by macrophages of the M1 phenotype in this strain.

Macrophages have been found not only in the limbus, iris, or trabecular meshwork but are also known to be present within the corneal stroma [33, 34]. Macrophages 


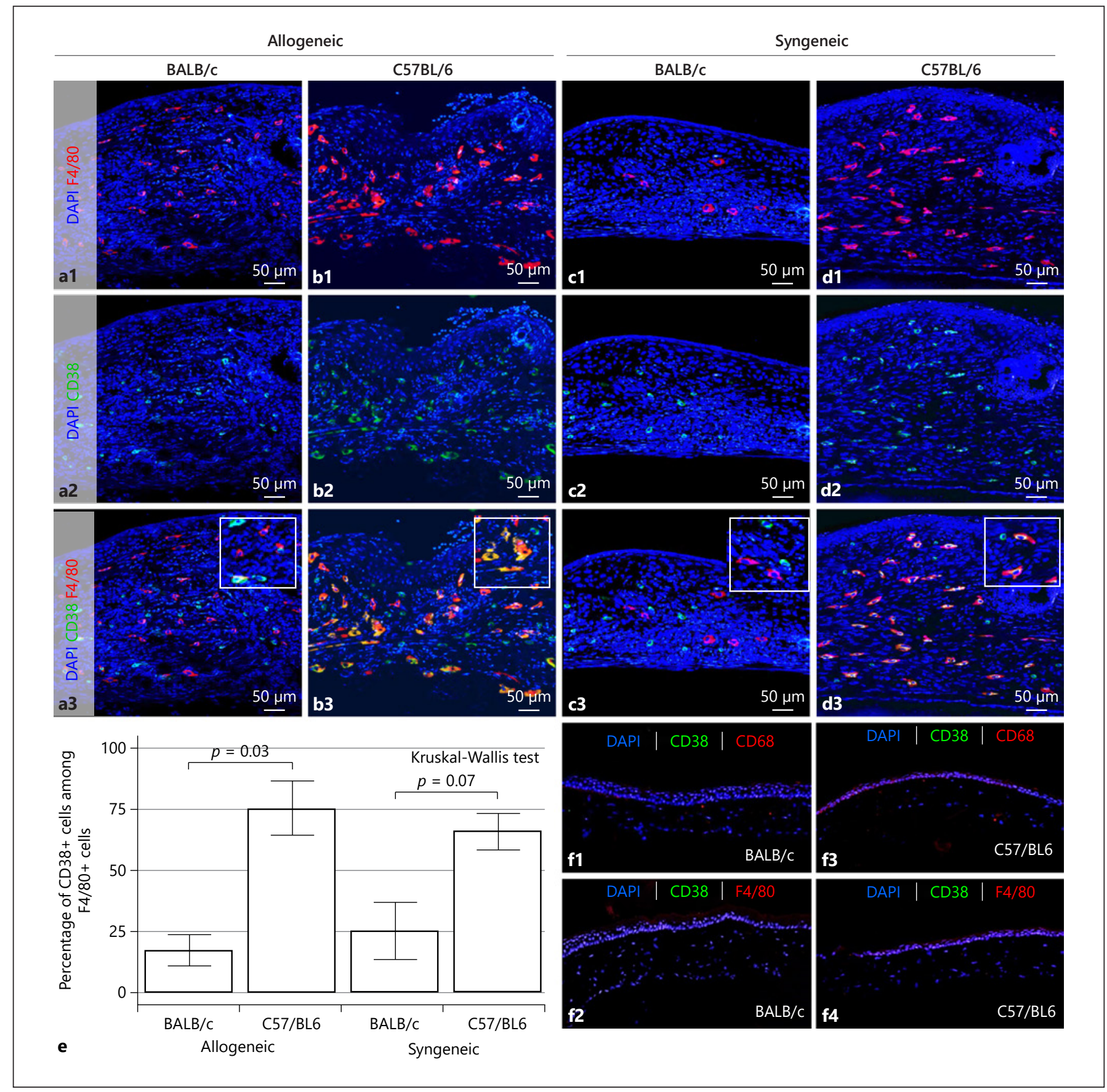

Fig. 4. Examples of immunohistochemistry of corneal transplants 18 to 21 days after transplantation. a-d The epithelium is located at the top of the image and the endothelium at the bottom. Antimouse F4/80 (red, first row) and anti-mouse CD38 (green, second row) antibodies were used to identify M1 macrophages. DAPI (blue) was used for nuclear staining. The box plots (e) represent the percentages of CD38 + cells among the F4/80 + macrophages as shown in a-d. The percentages of CD38 + cells among the F4/80 + cells were counted from the immunohistochemical slides as above ( $n=3$ animals were analyzed for the calculation, except $n=$ 4 in the allogeneic BALB/c group). Statistics were calculated using the Kruskal-Wallis test; the results are presented as mean \pm SEM. In untreated, non-transplanted mice, only sparse CD68 + or F4/80 + cells can be detected, that do not stain for CD38 (f). 
were recognized in 1985 as one of the major cell types infiltrating rejected human corneal grafts [35]. Depletion of macrophages by subconjunctival injection of clodronate liposomes, a macrophagicidal drug, significantly prolonged corneal graft survival [36] thereby strongly suggesting a significant role of macrophages in the initiation of corneal graft rejection. When Liu and colleagues transplanted corneas from GFP + mice to WT mice, GFP + APC appeared in the lymph nodes of WT recipients [37], confirming the evasion of donor APC from the transplant. Beige nude mice failed to reject corneal grafts from $\mathrm{BALB} / \mathrm{c}$ mice, indicating that macrophages alone are insufficient to induce rejection. However, rejection occurred in the presence of CD4+ T cells sensitized against $\mathrm{BALB} / \mathrm{c}$ mice [38]. Taken together, these data indicate that macrophages play an important role as APC in the afferent arm of corneal graft rejection.

When stimulated with human allogeneic corneal tissue, human monocyte-derived macrophages (MDM) induced the recruitment of further immunocompetent cells, which is seen as an initial step of corneal rejection [39]. In clinical samples from human patients, there is a significant influx of CD45+ monocyte-derived macrophages into the anterior chamber in the early phase of graft rejection [40]. Mounting evidence suggests that macrophages differentiate into a wide spectrum of intermediate phenotypes with different immunoregulatory capabilities. The categorization of macrophages in M1 and M2 subtypes and further differentiation into M2aM2d is controversial and anything but simple, but most accepted [41].

The biology and functions of the different macrophage subtypes have been studied extensively in mouse and man. However, very little is known about the function of different macrophage subtypes in corneal graft rejection. In mice, M1 macrophages display pro-inflammatory properties, representing an important source of reactive oxygen and nitrogen intermediates and of pro-inflammatory cytokines. On the other hand, M2 macrophages mediate resistance to parasites, wound healing, tissue remodelling, and resolution of inflammation [19]. Immunohistochemistry revealed a striking predominance of $\mathrm{CD} 38+\mathrm{F} 4 / 80$ + cells in rejected grafts of C57BL/ 6 mice in our study. The presence of these M1 macrophages thus could be linked to a more aggressive graft rejection, altering the macrophage phenotype into a M2-dominated pattern, therefore might be a promising therapeutical approach. Tahvildari et al. [26] injected IL-10 subconjunctivally to induce the generation of "tolerant APC" in mice, which significantly prolonged corneal graft survival. In- terestingly, IL-10 is the major cytokine for M2 induction $[41,42]$. Thus, the effect of IL-10 may be M2 mediated. This suggests IL-10 as an interesting compound to suppress corneal graft rejection by modulation of the macrophage phenotype within the graft.

We acknowledge that this study is limited by the fact that we evaluated the M1 phenotype in F4/80 macrophages only using CD38 as a marker. Immunophenotyping of both - human and murine - corneas remains incomplete compared with other tissues. Work in this area shows that various APCs are present in the cornea; these cells include macrophages, dendritic cells, and Langerhans cells [43]. Further work is needed on both: the phenotyping of immune cells in the cornea as well as on the function of different APC in the cornea. Moreover, the role of CD38 in the eye is still unclear. Under basal conditions, corneas in our study did not show a positive staining for CD38; only after transplantation, a large number of CD38-positive cells could be detected. These cells were mainly co-stained with $\mathrm{F} 4 / 80$ in C57BL/ 6 animals but not in $\mathrm{BALB} / \mathrm{c}$ animals.

In summary, our study provides evidence on why $\mathrm{BALB} / \mathrm{c}$ and $\mathrm{C} 57 \mathrm{BL} / 6 \mathrm{~J}$ mice respond differently after syngeneic corneal transplantation. M1 macrophages appear to play a crucial role in this process. Our study is the first to compare multiple aspects of corneal rejection between M1- and M2-dominated immune response models, namely $\mathrm{C} 57 \mathrm{BL} / 6 \mathrm{~J}$ and $\mathrm{BALB} / \mathrm{c}$ mice. These mouse strains are two of the most widely used models for rejection studies $[7-9,12,24,25,27,44,45]$. The results of our study indicate that these studies deserve cautious interpretation. On the other hand, the clear differences between these 2 models suggest a wide range of clinical and scientific applications. The BALB/c-recipient model could be used as a surgical control for corneal transplantation experiments, whereas models using C57BL/6 as recipients with the severe inflammation and the high rejection rate may serve as "high-risk" models for corneal transplantation.

\section{Acknowledgement}

No further relevant acknowledgements apply for this work.

\section{Statement of Ethics}

All animal experiments were approved by the Faculty of Medicine, University of Freiburg, and the federal state of Baden-Württemberg represented by the regional council Freiburg. This animal study was conducted in accordance with the ARVO Statement for 
the Use of Animals in Ophthalmic and Vision Research. Animals were also treated in compliance with German, European, and Federation of Laboratory Animal Science Associations (LAS) regulations for the care of experimental animals.

\section{Conflict of Interest Statement}

We confirm that all authors concur with the submission. All funding for the studies in the manuscript, together with the names of the principal funding recipients, are listed in the text. This work has not been published elsewhere, neither completely, nor in part, nor in another form. The manuscript has not been submitted to another journal and will not be published elsewhere. The manuscript does contain data derived from animal experiments. This study was approved by the Faculty of Medicine of the University of Freiburg and by the federal state of Baden-Württemberg represented by a regional council. Animals were treated in accordance with the European Union regulations for the care of experimental animals. This animal study was conducted in accordance with the ARVO Statement for the Use of Animals in Ophthalmic and Vision Research. Animals were also treated in compliance with German, European, and Federation of Laboratory Animal Science Associations (LAS) regulations for the care of experimental animals. No financial/commercial conflicts of interest have been disclosed.

\section{Funding Sources}

This work was supported by a grant from the GeschwisterFreter-Foundation, Langenhagen/Hannover, Germany (TB).

\section{Author Contributions}

T.L., T.B., C.L., and G.S.: conceptualization. T.B., X.Z., A.H., and D.B.: data curation. T.B., X.Z., A.H., T.L., and D.B.: formal analysis. T.B. and T.L.: funding acquisition. T.B., X.Z., A.H., and D.B.: investigation. T.B., X.Z., A.H., C.L., D.B., G.S., T.R., and T.L.: methodology. T.L. and G.S.: project administration and supervision. T.B., X.Z., C.L., G.S., T.L., and D.B.: validation. T.B., X.Z., T.L., and D.B.: visualization. T.B. and X.Z.: writing - original draft. A.H., C.L., D.B., G.S., T.R., and T.L.: writing - review and editing.

\section{References}

1 Gain P, Jullienne R, He Z, Aldossary M, Acquart $\mathrm{S}$, Cognasse $\mathrm{F}$, et al. Global survey of corneal transplantation and eye banking. JAMA Ophthalmol. 2016 Feb 1;134(2):16773.

2 Williams KA, Lowe M, Bartlett C, Kelly TL, Coster DJ, A Contributors. Risk factors for human corneal graft failure within the Australian corneal graft registry. Transplantation. 2008 Dec 27;86(12):1720-4.

3 Price FW, Price DA, Ngakeng V, Price MO. Survey of steroid usage patterns during and after low-risk penetrating keratoplasty. Cornea. 2009 Sep;28(8):865-70.

4 Hengge UR, Ruzicka T, Schwartz RA, Cork MJ. Adverse effects of topical glucocorticosteroids. J Am Acad Dermatol. 2006 Jan;54(1): $1-15$.

5 Leske MC, Chylack LT, Wu SY. The lens opacities case-control study. Risk factors for cataract. Arch Ophthalmol. 1991 Feb;109(2): 244-51.

6 Jin Y, Shen L, Chong EM, Hamrah P, Zhang $\mathrm{Q}$, Chen L, et al. The chemokine receptor CCR7 mediates corneal antigen-presenting cell trafficking. Mol Vis. 2007 Apr 27;13:62634.

7 Pastak M, Kleff V, Saban DR, Czugala M, Steuhl KP, Ergün S, et al. Gene therapy for modulation of $\mathrm{T}$ cell mediated immune response provoked by corneal transplantation. Hum Gene Ther. 2018 Apr 1;29(4):467-79.

8 Reuer T, Schneider AC, Cakir B, Bühler AD, Walz JM, Lapp T, et al. Semaphorin 3F modulates corneal lymphangiogenesis and promotes corneal graft survival. Invest Ophthalmol Vis Sci. 2018 Oct 1;59(12):5277-84.
9 Wang H, Zhao Q, Luo D, Yin Y, Li T, Zhao M. Resolvin E1 inhibits corneal allograft rejection in high-risk corneal transplantation. Invest Ophthalmol Vis Sci. 2018 Aug 1;59(10): 3911-9.

10 She SC, Steahly LP, Moticka EJ. A method for performing full-thickness, orthotopic, penetrating keratoplasty in the mouse. Ophthalmic Surg. 1990 Nov;21(11):781-5.

11 Joo CK, Pepose JS, Stuart PM. T-cell mediated responses in a murine model of orthotopic corneal transplantation. Invest Ophthalmol Vis Sci. 1995 Jul;36(8):1530-40.

12 Lapp T, Hildebrand A, Böhringer D, Betancor PK, Schlunck G, Reinhard T. Optimizing rejection readouts in a corneal allograft transplantation model. Mol Vis. 2016;22:1248-55.

13 Scott PA, Farrell JP. Experimental cutaneous leishmaniasis: disseminated leishmaniasis in genetically susceptible and resistant mice. Am J Trop Med Hyg. 1982 Mar 1;31(2):230-8.

14 Heinzel FP, Sadick MD, Locksley RM. Leishmania major: analysis of lymphocyte and macrophage cellular phenotypes during infection of susceptible and resistant mice. Exp Parasitol. 1988 Apr;65(2):258-68.

15 Bertolini TB, de Souza AI, Gembre AF, Piñeros AR, Prado RdQ, Silva JS, et al. Genetic background affects the expansion of macrophage subsets in the lungs of mycobacterium tuberculosis-infected hosts. Immunology. 2016 May; 148(1):102-13.

16 Foerster F, Boegel S, Heck R, Pickert G, Rüssel $\mathrm{N}$, Rosigkeit $\mathrm{S}$, et al. Enhanced protection of $\mathrm{C} 57 \mathrm{BL} / 6$ vs $\mathrm{BALB} / \mathrm{c}$ mice to melanoma liver metastasis is mediated by NK cells. OncoImmunology. 2018 Apr 3;7(4):e1409929.
17 Fornefett J, Krause J, Klose K, Fingas F, Hassert R, Benga L, et al. Comparative analysis of humoral immune responses and pathologies of BALB/c and C57BL/ 6 wildtype mice experimentally infected with a highly virulent Rodentibacter pneumotropicus (Pasteurella pneumotropica) strain. BMC Microbiol. 2018 May 30;18(1):45.

18 Jiang X, Shen C, Yu H, Karunakaran KP, Brunham RC. Differences in innate immune responses correlate with differences in murine susceptibility to Chlamydia muridarum pulmonary infection. Immunology. 2010; 129(4):556-66.

19 Mills CD, Kincaid K, Alt JM, Heilman MJ, Hill AM. M-1/M-2 Macrophages and the Th1/Th2 paradigm. J Immunol. 2000 Jun 15; 164(12):6166-73.

20 Wang X, Qu M, Li J, Danielson P, Yang L, Zhou Q. Induction of fibroblast senescence during mouse corneal wound healing. Invest Ophthalmol Vis Sci. 2019 Aug 1;60(10):366979.

21 Li S, Li L, Zhou Q, Gao H, Liu M, Shi W. Blood vessels and lymphatic vessels in the cornea and iris after penetrating keratoplasty. Cornea. 2019 Jun;38(6):742-7.

22 Jiang L, Liu T, Xie L, Ouyang C, Ji J, Huang T. AICAR prolongs corneal allograft survival via the AMPK-mTOR signaling pathway in mice. Biomed Pharmacother. 2019 May 1;113: 108558.

23 Shamloo K, Barbarino A, Alfuraih S, Sharma A. Graft versus host disease-associated dry eye: role of ocular surface mucins and the effect of rebamipide, a mucin secretagogue. Invest Ophthalmol Vis Sci. 2019 01;60(14):4511-9. 
24 Yamada J, Streilein JW. Induction of anterior chamber-associated immune deviation by corneal allografts placed in the anterior chamber. Invest Ophthalmol Vis Sci. 1997;38(13): 2833-2843.

25 Tan Y, Abdulreda MH, Cruz-Guilloty F, Cutrufello N, Shishido A, Martinez RE, et al. Role of T Cell Recruitment and ChemokineRegulated Intra-Graft T Cell Motility Patterns in Corneal Allograft Rejection. Am J Transplant. 2013;13(6):1461-1473.

26 Tahvildari M, Emami-Naeini P, Omoto M, Mashaghi A, Chauhan SK, Dana R. Treatment of donor corneal tissue with immunomodulatory cytokines: a novel strategy to promote graft survival in high-risk corneal transplantation. Sci Rep. 2017;7(1):971.

27 Inomata T, Hua J, Nakao T, Shiang T, Chiang $\mathrm{H}$, Amouzegar A, et al. Corneal Tissue from Dry Eye Donors Leads to Enhanced Graft Rejection. Cornea. 2018;37(1):95-101.

28 Sano Y, Ksander BR, Streilein WS. Minor H, rather than $\mathrm{MHC}$, alloantigens offer the greater barrier to successful orthotopic corneal transplantation in mice. Transpl Immunol. 1996;4(1):53-56.

29 Gasser L, Reinhard T, Böhringer D. Comparison of corneal endothelial cell measurements by two non-contact specular microscopes. BMC Ophthalmol. 2015 Jul 29;15:87.

30 R Core Team. R: a language and environment for statistical computing. Vienna, Austria: R Foundation for Statistical Computing; 2017. Available from: https://www.R-project.org/.

31 Wickham H. ggplot2: Elegant graphics for data analysis. New York: Springer-Verlag; 2016.

32 Harrell FE. Harrell miscellaneous [internet] 2019. Available from: http://biostat.mc. vanderbilt.edu/Hmisc.
33 Brissette-Storkus CS, Reynolds SM, Lepisto AJ, Hendricks RL. Identification of a novel macrophage population in the normal mouse corneal stroma. Invest Ophthalmol Vis Sci. 2002 Jul;43(7):2264-71.

34 Yamagami S, Ebihara N, Usui T, Yokoo S, Amano S. Bone marrow-derived cells in normal human corneal stroma. Arch Ophthalmol. 2006 Jan 1;124(1):62-9.

35 Pepose JS, Nestor MS, Gardner KM, Foos RY, Pettit TH. Composition of cellular infiltrates in rejected human corneal allografts. Graefes Arch Clin Exp Ophthalmol. 1985;222(3):12833.

36 Slegers TP, Torres PF, Broersma L, van Rooijen N, van Rij G, van der Gaag R. Effect of macrophage depletion on immune effector mechanisms during corneal allograft rejection in rats. Invest Ophthalmol Vis Sci. 2000 Jul 1;41(8):2239-47.

37 Liu Y, Hamrah P, Zhang Q, Taylor AW, Dana MR. Draining lymph nodes of corneal transplant hosts exhibit evidence for donor major histocompatibility complex (MHC) class IIpositive dendritic cells derived from $\mathrm{MHC}$ class II-negative grafts. J Exp Med. 2002 Jan 21;195(2):259-68.

38 Hegde S, Beauregard C, Mayhew E, Niederkorn JY. CD4(+) T-cell-mediated mechanisms of corneal allograft rejection: role of Fas-induced apoptosis. Transplantation. 2005 Jan 15;79(1):23-31.

39 Betancor PK, Hildebrand A, Böhringer D, Emmerich F, Schlunck G, Reinhard T, et al. Activation of human macrophages by human corneal allogen in vitro. PLoS One. 2018 Apr 4;13(4): $\mathrm{e} 0194855$.

40 Lapp T, Zaher SS, Haas CT, Becker DL, Thrasivoulou C, Chain BM, et al. Identification of therapeutic targets of inflammatory monocyte recruitment to modulate the allogeneic injury to donor cornea. Invest Ophthalmol Vis Sci. 2015 Nov 1;56(12):7250-9.
41 Murray PJ, Allen JE, Biswas SK, Fisher EA Gilroy DW, Goerdt S, et al. Macrophage activation and polarization: nomenclature and experimental guidelines. Immunity. $2014 \mathrm{Jul}$ 17;41(1):14-20.

42 Mosser DM, Edwards JP. Exploring the full spectrum of macrophage activation. Nat Rev Immunol. 2008 Dec;8(12):958-69.

43 Novak N, Siepmann K, Zierhut M, Bieber T. The good, the bad and the ugly: APCs of the eye. Trends Immunol. 2003 Nov;24(11):570-4.

44 Hegde S, Niederkorn JY. The role of cytotoxic T lymphocytes in corneal allograft rejection. Invest Ophthalmol Vis Sci. 2000 Oct 1; 41(11):3341-7.

45 Lee HS, Kwon JY, Joo CK. Comparative immunological study of penetrating and anterior lamellar keratoplasty in a murine model. Exp Eye Res. 2018;169:141-8.

46 Waddell LA, Lefevre L, Bush SJ, et al. ADGRE1 (EMR1, F4/80) Is a Rapidly-Evolving Gene Expressed in Mammalian Monocyte-Macrophages. Front Immunol. 2018;9:2246. doi: 10.3389/fimmu.2018.02246.

47 Gordon S, Hamann J, Lin HH, Stacey M. F4/80 and the related adhesion-GPCRs. Eur J Immunol. 2011;41(9):2472-6. doi: 10.1002/ eji.201141715.

48 Jablonski KA, Amici SA, Webb LM, et al Novel Markers to Delineate Murine M1 and M2 Macrophages. PLoS One. 2015;10(12): e0145342.doi:10.1371/journal.pone.0145342.

49 Ishibashi T, Yokota T, Satoh Y, et al. Identification of MS4A3 as a reliable marker for early myeloid differentiation in human hematopoiesis. Biochem Biophys Res Commun. 2018; 495(3):2338-43. doi: 10.1016/j.bbrc.2017.12. 117.

50 Amici SA, Young NA, Narvaez-Miranda J, et al. CD38 Is Robustly Induced in Human Macrophages and Monocytes in Inflammatory Conditions. Front Immunol. 2018;9:1593. doi: 10.3389/fimmu.2018.01593. 